\title{
Brachial Artery FMD and Endothelial Responses to High-Intensity Interval and Steady-State Moderate-Intensity Exercise
}

\author{
JEFFREY S. FORSSE, ZACH PAPADAKIS, ANNIE A. BANE, FLOR ELISA MORALES \\ MARROQUÍN, PETER W. GRANDJEAN (FACSM).
}

Department of Health, Human Performance, and Recreation, Baylor University, Waco,

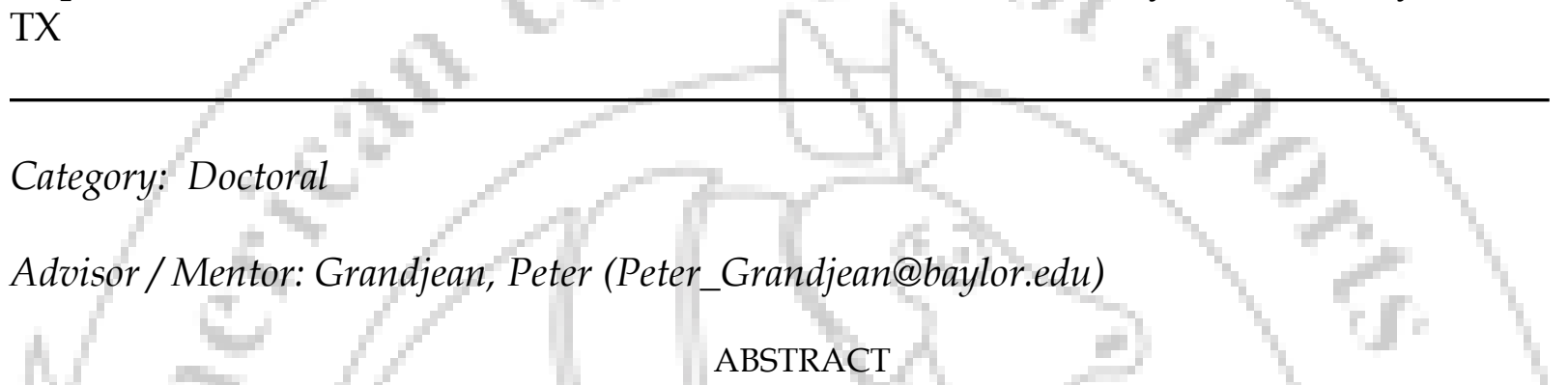

Brachial artery flow-mediated dilation (FMD) is a nitric oxide-dependent measure of conduit artery endothelial function that is potentiated by moderate- and high-intensity steady state exercise (SSE) for up to an hour after exercise; however, it is unclear whether high-intensity interval exercise (HIIE) provides a longer-lasting stimulus for enhancing FMD or greater oxidative and nitrative stress on the vascular endothelium than a comparable or greater amount of SSE. PURPOSE: Determine the influence of HIIE on post-exercise brachial artery FMD and the relationship between FMD and markers of endothelial function relative to a comparable amount of moderate-intensity SSE and a dose that is half that of SSE. METHODS: Seventeen male participants (age $27.8 \pm 6.4 \mathrm{yr}$; weight $80.6 \pm 9.0 \mathrm{~kg}$; BMI $25.1 \pm 2.4 \mathrm{~kg} / \mathrm{m} 2$; VO2max $52.1 \pm$ $7.5 \mathrm{ml} / \mathrm{kg} / \mathrm{min}$ ) underwent HIIE by treadmill running ( $90 \%$ and $40 \%$ of VO2reserve in $3: 2$ min ratio) to expend 500 kcals; HIIE to expend $250 \mathrm{kcals}$, and; SSE at $70 \% \mathrm{VO}_{2}$ reserve to expend $500 \mathrm{kcals}$ in a randomized crossover design. All exercise conditions averaged $70 \% \mathrm{VO}_{2}$ reserve. Ultrasound measurements of brachial artery FMD and blood measures of total antioxidant capacity (TAC) in copper reducing equivalents, apolipoprotein A-1 (ApoA1: g/L), PON1 concentration (PON1c: $\mu \mathrm{g} / \mathrm{mL}$ ), arylesterase activity (PON1a: $\mathrm{kU} / \mathrm{L}$ ), soluble vascular adhesion molecule-1 (sVCAM-1: $\mathrm{ng} / \mathrm{mL}$ ) and nitrotyrosine (NT: nM) were obtained just before and $2 \mathrm{hr}$ after exercise. FMD responses to exercise were analyzed using 3 (condition) by 2 (sample point) repeated measures ANOVAs. Pearson product-moment correlations of change variables ( $2 \mathrm{hr}$ post-exercise - pre-exercise values) were calculated to determine relationships between FMD responses and blood variable responses to exercise. RESULTS: Brachial artery FMD responses were unaltered $2 \mathrm{hr}$ after exercise in all three conditions $(\mathrm{p}>0.05)$. FMD responses were correlated with changes in PON1c $(r=0.221, p<0.0001)$ and inversely with changes TAC $(r=-0.170, p<$ $0.0001)$. Changes in s-VCAM1 were correlated with change in NT $(r=0.423, p<0.0001)$ and inversely with changes in PON1c $(\mathrm{r}=-0.177, \mathrm{p}<0.0001)$. SUMMARY: Brachial artery FMD is unaltered $2 \mathrm{hr}$ after HIIE or SSE of moderate duration in young fit men and does not appear to be related to responses in other markers of endothelial function.

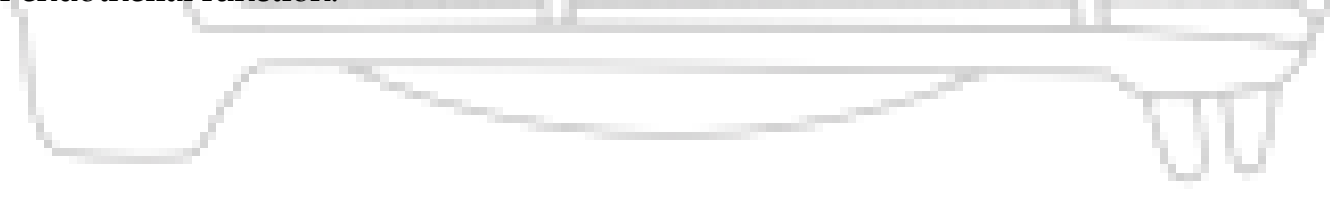

